\title{
The Effects of Using the Classroom Response System in Teacher Education
}

\author{
Fu-Hsing Tsai
}

\begin{abstract}
The classroom response system (CRS) has gradually become a popular instructional technology in classrooms. This study aimed to integrate CRS into a teacher education course to investigate preservice teachers' perceptions and their use behaviors. A total of $\mathbf{3 5}$ preservice teachers from a university in Southern Taiwan were recruited as the research participants of this study. Each participant used CRS throughout the semester in an educational theory course related to curriculum development and design. The research findings revealed that CRS use can increase learning motivation of preservice teachers in the teacher education course and enhance their willingness to utilize CRS in their future teaching. Furthermore, a significant positive correlation was found between the preservice teachers' CRS behaviors and their course grades. The result indicated that CRS use enables a teacher to effectively determine student learning statuses, and thereby predict their learning outcomes.
\end{abstract}

Index Terms-Classroom response system, teacher education, instructional technology, learning effect.

\section{INTRODUCTION}

With the prevalent use of personal computers and the Internet, a number of countries have implemented educational reforms that involve the active use of information and communication technologies (ICTs) [1]. Following this trend of innovative teaching through employing ICTs, multiple countries have invested substantial funding to increase information infrastructures in primary and secondary schools. For example, from 2001 to 2004, the UK invested 25 million GBP annually to install interactive whiteboards (IWBs) in primary and secondary school classrooms. Statistical results as of April 2006 showed that $86 \%$ of the primary schools and $97 \%$ of the secondary schools in England had been equipped with IWBs [2]. The American Recovery and Reinvestment Act of 2009 proposed by the US, also included investing US\$650 million to ensure technology integration in schools. Furthermore, the 5-year National Educational Technology Plan 2010, proposed in March 2010, was designed to generate appealing learning experiences, content and methods by using ICTs.

Numerous technological products that assist teaching by using ICTs such as desktop personal computers, the Internet, handheld mobile carriers, IWBs and opaque projectors have

Manuscript received August 4, 2017; revised September 15, 2017. This work was supported in part by the Ministry of Science and Technology, Taiwan under contract numbers MOST 104-2511-S-415-010-MY2 and MOST 106-2511-S-415-005.

Fu-Hsing Tsai is with the Teacher Education Center, National Chiayi University, 85, Wunlong Village, Minsyong Township, 62103 Chiayi County, Taiwan (e-mail: fhtsai@mail.ncyu.edu.tw). become commonly available in classrooms. In addition, the classroom response system (CRS) has gradually become another commonly seen technological teaching aid in classrooms. Although it is also referred to as an audience response system (ARS), electronic response system (ERS), or simply as clickers [3]-[5], it generally comprises three important components: a simple handheld electronic device, the receiver and the response system software. When using the CRS in classroom, each student is provided a handheld electronic device with which the students can transmit their answers, related to the true-false or multiple-choice questions that the teacher asks, via wireless signals such as infrared ray or Wi-Fi. Subsequently, through a receiver, the corresponding response system software can quickly collect, calculate and analyze student responses. Therefore, the teacher can immediately present the calculated results to the students by using a projector or IWB, and the students can quickly understand whether their answer is correct, as well as the correct ratio of the whole class. Hence, this technology is often applied before a lesson to enable the teacher to quickly understand students' prior abilities; it can also be used during or after teaching to enable the teacher to quickly conduct a formative or summative assessment [6]. Numerous studies have confirmed that employing CRS can effectively improve students' class attendance [7], learning motivation and interaction [8], and learning performance [9].

Teacher education plays an important role in promoting teachers' use of ICTs in teaching. Studies have shown that preservice teachers who possess ICT abilities exhibit higher willingness and self-efficacy in using ICTs in their teaching after they become certified teachers [10]-[12]. Therefore, several scholars have asserted that teacher education institutions should consistently provide related courses to develop preservice teachers' abilities to use ICTs in their teaching [13]. Nevertheless, related studies indicate that improvements are needed in the fostering of preservice teachers' ICT abilities. A common problem is that a number of teacher education institutions only offer preservice teachers with one course related to instructional technology [14]. Moreover, because that course tends to focus on the operation skill of ICTs [15], and the college teachers of other teacher education courses do not often use ICT in class, many preservice teachers are not sufficiently exposed to ICT applications in teaching during their teacher education [10], [16]. In other words, even though preservice teachers could become familiar with the operation skill of ICTs such as CRS through a course related to instructional technology, they are not exposed to CRS in the long term on how to actually apply CRS in teaching.

This phenomenon also commonly occurs in Taiwanese teacher education institutions. Following the regulations of 
the Ministry of Education, all Taiwanese teacher education institutions provide a course titled "Instructional Media and Application" to develop the ICT abilities of preservice teachers. However, this course tends to emphasize the operation skill of ICTs. Therefore, after finishing the course, most preservice teachers still do not receive sufficient opportunities to experience using ICTs in their teaching, because most other teacher education courses focus on education theories and rarely involve ICTs because not every college teacher in the teacher education program possesses ICT expertise.

By addressing the fact that CRS has gradually become a common instructional technology in the classroom, and few previous studies have focused on preservice teachers, this study aimed to integrate CRS into a teacher education course related to education theory offered by a teacher education institution in Taiwan for preservice teachers. This study investigated preservice teachers' perceptions about CRS application in teaching and their future intention about using CRS in teaching after using the CRS in an educational theory course. Furthermore, this study also analyzed how the preservice teachers' use of CRS influenced their learning performance during the course.

\section{METHOD}

\section{A. Participants}

The participants of this study were preservice teachers enrolled in a teacher education program for primary school teachers at a university in Southern Taiwan. These preservice teachers need to acquire 40 credits in the teacher education program based on the regulations of the Ministry of Education in Taiwan. However, among all courses consistently offered by this university, only one is related to ICT, namely "Instructional Media and Application." This course primarily teaches important ICT skills that are applicable when teaching in primary schools, including the skills of word processing and digital presentation. In general, only one to two class sessions are devoted to introducing preservice teachers to CRS applications. Nonetheless, except for this course, no teacher had used CRS for teaching in the other teacher education courses in the program. Hence, to enhance preservice teachers' ICT application abilities and to identify their perceptions on CRS usage in teaching, this study incorporated CRS into a teacher education course called "Curriculum Development and Design" in this teacher education program. The course was a two-credit course dedicated to teaching students theories on curriculum design. It comprised two class sessions each week for 18 weeks in total. A total of 35 preservice teachers enrolled in this course. Therefore, these 35 preservice teachers were recruited as the research participants of this study.

\section{B. Procedure}

To record each participant's CRS usage behavior, every preservice teacher was given a personal CRS handheld electronic device during the first session of the course. The instructor of the course used the CRS in class nearly every week. For example, after instructing a learning unit, the instructor spent approximately $20 \mathrm{~min}$ using CRS for assessing the preservice teachers' knowledge acquisition with multiple-choice questions related to the learning unit just taught. When all preservice teachers completed a question, the instructor immediately announced the correct answer and the correct answer ratio of the whole class generated by the response system software, and provided explanations for the questions that generated a higher error rate. To understand these preservice teachers' perceptions after using the CRS, all participants were asked to complete a self-developed perception scale in the last session of the course. Moreover, each preservice teacher's CRS use behavior throughout the semester was completely recorded in the database of the CRS software, facilitating subsequent research and analysis.

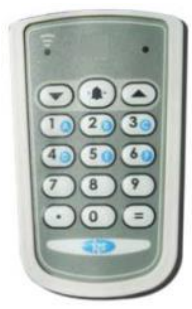

Fig. 1. CRS remote control.

\section{Instruments}

\section{1) $C R S$}

This study used the commercial version of a CRS created by HABOOK Information Technology, Taiwan. The Company refers to the CRS as an interactive response system, IRS, which comprises a handheld remote control used by the student (see Fig. 1), a receiver (see Fig. 2), and the response system software (see Fig. 3). To use this CRS, the receiver must be plugged into the USB port on the instructor's computer in the classroom. The response system software should be installed on the instructor's computer as well. Consequently, the students can use the handheld remote control to answer the multiple choice questions the teacher asks by pressing the number buttons on the remote control. The receiver and response software can receive, record and analyze in real time all the answers the students send. In addition, the response software provides a user-friendly interface as well as comprehensive functions with which the teacher can establish students' personal data and set the serial number of the remote control used by each student before the class begins (see Fig. 3). Therefore, the teacher can correctly record the answer of each student for in-class CRS activities. In addition, this CRS is effectively integrated with PowerPoint, widely applied software used by most teachers, to aid the teacher in editing assessment questions through the PowerPoint interface.

\section{2) User perception scale}

To understand the perceptions of the preservice teachers after using the CRS for one semester, this study developed a user perception scale for the participants to complete at the end of the semester. This scale comprised nine questions that were measured on a five-point scale (Table I presents all the questions). Cronbach's $\alpha$ of the overall scale was .86 . Furthermore, to enable the collection of authentic perceptions 
of the participants, one open question was included that enabled the teachers to freely write down their reflections or suggestions.

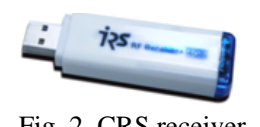

Fig. 2. CRS receiver.

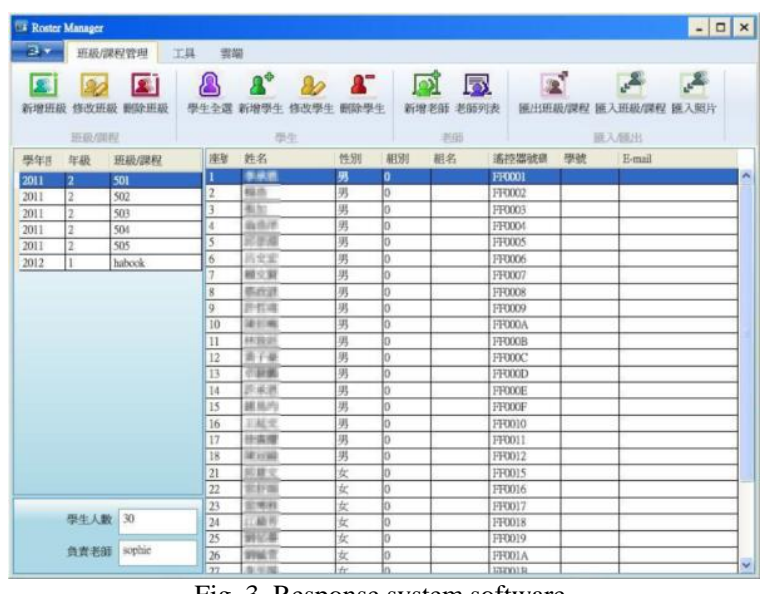

Fig. 3. Response system software.

\section{RESULtS}

\section{A. Survey Results of Preservice Teachers' Perceptions on Using CRS}

To understand the preservice teachers' perceptions of using CRS in an ordinary educational theory course, the participants were requested to complete a self-developed perception scale at the end of the course. Moreover, to quantify the preservice teachers' perceptions, the answers of the perception scale were represented by scores of 5 (strongly agree) to 1 (strongly disagree). The average score of the overall scale was 4.12, with the average score of each question shown in Table I. The statistical results revealed that the preservice teachers generated a considerably positive response to the application of CRS in their educational theory course. Specifically, most of the preservice teachers enjoyed using the CRS in class, and reported that the CRS enhanced learning motivation and rendered the class more interesting and stimulating. The results implied that most of the preservice teachers thought that using CRS facilitates improved their learning motivation in the educational theory class. In addition, most of the preservice teachers regarded the CRS as a satisfactory teaching aid, particularly because it presented the extent to which they grasped the course content in real time. The results implied that most of the preservice teachers believed that the CRS enhanced the learning effectiveness related to educational theories. Furthermore, regarding the willingness of applying a CRS in the future, most of the preservice teachers specified that they wished to use a CRS in teaching when they become teachers, indicating that this experimental course exerted a positive effect on the preservice teachers' willingness to use CRS in the future.

Most of the preservice teachers provided positive reflections to the open question in the user perception scale. A few examples are presented as follows: "Using a CRS enriches the curriculum and aids students in focusing on learning." "This course serves as a teaching example of how teachers can use a CRS. The preservice teachers acquire another applicable teaching skill and tool through taking this course." "I feel the class becomes much more interesting, and that I have more interaction with the teacher in class." "Using the CRS in the course 'Curriculum Development and Design' facilitates motivating the students and enables the students to identify their problems in learning specific units." "Using a CRS is very interesting and assists me in immediately understanding the learning results." "I think the teacher's arrangement of having us take assessment questions by using the CRS works wonderfully. We can determine instantly to what extent we have grasped the class content." "I look forward to using a CRS every time in class. On the one hand, I can identify my level of comprehension of the class material right away; on the other hand, the CRS enables me to have a deeper memory. Most important of all, the CRS directly shows my level of comprehension. In addition, the teacher's subsequent explanation is very helpful to me because I can clarify my misunderstanding of the questions that I answered incorrectly. Therefore, using CRS in class exerts a positive effect." These opinions show that most of the preservice teachers believed that the CRS assisted them in enhancing learning motivation, facilitating learning and increasing ideas on using CRS.

TABLE I: RESULTS OF THE CRS USER PERCEPTION SURVEY

\begin{tabular}{|c|c|c|}
\hline Number & Question & Average score \\
\hline 1 & I like using the CRS in class. & 4.26 \\
\hline 2 & $\begin{array}{l}\text { I think using the CRS enhances my } \\
\text { learning motivation. }\end{array}$ & 4.20 \\
\hline 3 & I think using the CRS is interesting. & 4.31 \\
\hline 4 & $\begin{array}{l}\text { Using the CRS in class enables me to } \\
\text { immediately determine my level of } \\
\text { comprehension of the class materials. }\end{array}$ & 4.23 \\
\hline 5 & $\begin{array}{l}\text { I think using the CRS rendered me more } \\
\text { focused in class. }\end{array}$ & 3.94 \\
\hline 6 & $\begin{array}{l}\text { I looked forward to using the CRS every } \\
\text { week in class. }\end{array}$ & 3.83 \\
\hline 7 & $\begin{array}{l}\text { I wish that in the future, other courses in } \\
\text { the teacher education program would also } \\
\text { incorporate a CRS in class. }\end{array}$ & 3.86 \\
\hline 8 & $\begin{array}{l}\text { I wish to use a CRS in my class when I } \\
\text { become a teacher in the future. }\end{array}$ & 4.17 \\
\hline 9 & $\begin{array}{l}\text { I think the CRS is a wonderful teaching } \\
\text { aid. }\end{array}$ & 4.26 \\
\hline
\end{tabular}

\section{B. Analysis Results of the Preservice Teachers' CRS Use Behaviors}

To analyze the preservice teachers' CRS use behaviors in class, the participants' personal information and unique serial number of their individual handheld remote control were incorporated into the response system software before the experiment. Thus, throughout the semester, each preservice teacher's CRS use behaviors were recorded completely. This study first conducted the correlation analysis between each participant's correct answer rate obtained from answering questions in class by CRS and their midterm exam, final exam and end-of-semester grades of the course. Table II shows the analysis results. These results exhibit significant positive correlations between the preservice teachers' in-class CRS performance and their midterm exam, final exam and end-of-the-semester grades. In other words, 
preservice teachers who achieved higher in-class CRS performance were likely to obtain more satisfactory grades in the course. Specifically, the participants' in-class CRS performances showed a significant positive correlation of .69 with the end-of-the-semester grades. The findings seem to be reasonable because if the preservice teachers exerted sufficient effort in class, they would show better performance on CRS behaviors, and then they would receive higher end-of-the-semester grades. In other words, this analysis result implied that the preservice teachers' semester grades could be predicted from their in-class CRS question-answering performance. Therefore, if the teachers can appropriately analyze and apply the records collected from the CRS response software, then they can predict which students are likely to exhibit unsatisfactory learning performance, and thereby offer remedial teaching.

TABLE II: CORRELATION BETWEEN THE CRS BEHAVIORS AND LEARNING

\begin{tabular}{lccc}
\multicolumn{4}{c}{ PERFORMANCE } \\
\hline \hline & $\begin{array}{c}\text { Midterm } \\
\text { exam grades }\end{array}$ & $\begin{array}{c}\text { Final exam } \\
\text { grades }\end{array}$ & $\begin{array}{c}\text { End-of-semester } \\
\text { grades }\end{array}$ \\
\hline $\begin{array}{l}\text { Correct rate of } \\
\text { question-answering } \\
\text { in class by CRS }\end{array}$ & $.415^{*}$ & $.375^{*}$ & $.693^{*}$ \\
\hline \hline$* p<.05$ & & & \\
\hline
\end{tabular}

TABLE III: COMPARISON BETWEEN THE GRADES OF THE PRESERVICE TEACHERS WITH UNSATISFACTORY CLASS ATTENDANCE RATES AND THOSE OF THE ENTIRE CLASS

\begin{tabular}{lcc} 
& \multicolumn{3}{c}{ OF THE ENTIRE CLASS } & Entire class $(n=35)$ \\
& $\begin{array}{c}\text { Students with an } \\
\text { unsatisfactory class } \\
\text { attendance rate }(n=5)\end{array}$ & 82.06 \\
\hline $\begin{array}{l}\text { Average grades for the } \\
\text { midterm exam }\end{array}$ & 71.80 & 71.34 \\
$\begin{array}{l}\text { Average grades for the } \\
\text { final exam } \\
\begin{array}{l}\text { Average of the } \\
\text { end-of-semester grades }\end{array}\end{array}$ & 56.60 & 79.83 \\
\hline \hline
\end{tabular}

Secondly, an analysis of CRS user history also showed that among the 35 preservice teachers, five of them had two or more absences throughout the semester. Except for one preservice teacher, who was absent six times, the remaining four all had two absences. This showed that the attendance rate of the class was satisfactory; only five preservice teachers exhibited lower attendance rates. Table III shows the comparison of learning performance between the five preservice teachers who exhibited less satisfactory attendance rates and all the participants. The midterm exam, final exam and end-of-semester grades of the five preservice teachers were all lower than those of the class average. The preservice teacher who had six absences even failed in her end-of-semester grades. This result indicated that an unfavorable attendance rate affected the learning performance of the preservice teachers throughout the semester. Furthermore, Table IV shows the relationship between the five preservice teachers' midterm exam, final exam and end-of-semester grades and their rate of answering questions correctly in class with the CRS. The correlation value obtained in each item was higher than that observed in the entire class (see Table II). In particular, a significant correlation $(r=.978)$ exists between the aforementioned rate of correct responses and these five preservice teachers' end-of-semester grades. The results show that CRS performance was more effective in predicting the semester grade performance of preservice teachers with an unfavorable attendance rate. Consequently, a CRS can provide teachers with a clear view of students' attendance, which is helpful because attendance rates affect students' semester performance. In other words, by appropriately using CRS records, a teacher can determine student attendance at any time, thereby predicting and providing remedial teaching to students who may obtain unsatisfactory learning results.

TABLE IV: CORRELATION BETWEEN THE CRS BEHAVIORS AND LEARNING PERFORMANCE OF THE PRESERVICE TEACHERS WHO EXHIBITED AN UNSATISFACTORY ATTENDANCE RATE

\begin{tabular}{|c|c|c|c|}
\hline & $\begin{array}{c}\text { Midterm } \\
\text { exam grades }\end{array}$ & $\begin{array}{c}\text { Final exam } \\
\text { grades }\end{array}$ & $\begin{array}{c}\text { End-of-semester } \\
\text { grades }\end{array}$ \\
\hline $\begin{array}{l}\text { Correct rate of } \\
\text { question-answering } \\
\text { in class by CRS }\end{array}$ & .671 & $.801 *$ & $.978 *$ \\
\hline
\end{tabular}

\section{DISCUSSION AND CONCLUSION}

Previous studies on CRS application have mostly focused on elementary, secondary and college students or teachers. Few studies have investigated preservice teachers. However, preservice teachers play an important role in regard to whether the CRS can be widely integrated into the classroom in the future. Therefore, this study specifically recruited preservice teachers as participants to conduct a study on the perceptions and behaviors of preservice teachers regarding using CRS in teacher education courses. The results revealed that CRS use can increase the learning motivation of preservice teachers in educational theory courses. After using CRS for one semester, most of the preservice teachers reported that it increased their learning motivation $(M=4.20)$. The result supported previous studies that have indicated that CRS use increases learning motivation [8]. Moreover, most of the preservice teachers expressed their willingness to utilize CRS in teaching in the future $(M=4.17)$. This result is in line with those of previous studies, which have indicated that preservice teachers who possess ICT abilities exhibit a greater willingness to use ICT in future teaching practices [10]-[12]. Furthermore, CRS use enables a teacher to effectively determine students' learning status, and thereby predicts their learning outcomes. A significant positive correlation exists between the rate of correct CRS question answering throughout the semester and the semester grades of the preservice teachers. This result confirms previous studies' claim that CRS use can be applied for formative or diagnostic assessments [6].

The results of the CRS user perception survey of the preservice teachers indicate that most of the preservice teachers believe that using the CRS aided their learning. This result supports a previous research result that claimed that CRS can facilitate learning [9]. However, because this study only used one group as the research sample, no further evidence from control groups could be compared to confirm whether the learning outcome of the preservice teachers was enhanced by CRS use. Thus, future studies should recruit more participants and apply a more comprehensive experimental design to verify whether CRS use contributes to learning performance of preservice teachers in teacher 
education courses. In addition, the preservice teachers' use records of the CRS show that most of the preservice teachers exhibited a fairly high class attendance rate. This result supports a previous research result that indicated that CRS use can enhance class attendance [7]; however, no comparison could be conducted in this study because it only involved one group of participants. Further research remains to be conducted to confirm this finding.

The present study not only primarily confirmed that CRS use can increase preservice teachers' learning motivation, but also found that CRS is a useful tool for college teachers in teacher education programs. The analysis results of the preservice teachers' CRS use behaviors implies that if a teacher regularly observed students' CRS use behaviors by properly using the CRS records, then the teacher could easily predict the students' learning outcomes, and even provide remedial teaching or modify the teaching content for the students who exhibited unsatisfactory learning predictions. In addition, the results show that long-term use of CRS enhanced the willingness of preservice teachers to use CRS in the future. Therefore, CRS is a worthy recommendation to the college teachers in teacher education courses. Because of funding limitations, many schools may not be able to purchase CRS for providing each teacher with an exclusive set of the commercial version, which was used in this study. However, because handheld mobile device use (i.e. cellphones and tablet computers) have become prevalent, a growing number of mobile device applications and CRS cloud systems enable cellphones or tablet computers to serve as replacements of the commercial CRS. Therefore, by appropriately employing available resources, college teachers should be able to use CRS easily in teacher education courses. In the future, a comparison should be made regarding the differences in the use of different CRS devices.

\section{ACKNOWLEDGMENT}

This research received financial support from the Ministry of Science and Technology of Taiwan under contract numbers MOST 104-2511-S-415-010-MY2 and MOST 106-2511-S-415-005.

\section{REFERENCES}

[1] C. Greenhow, B. Robelia, and J. E. Hughes, "Learning, teaching, and scholarship in a digital age: Web 2.0 and classroom research: What path should we take now?" Educational Researchers, vol. 38, no. 4, pp. 246-259, 2009
[2] C. Clarke, "Opening address to the BETT conference," presented at BETT 2004, Olympia, London, January 7, 2004.

[3] D. Duncan, "Clickers: A new teaching aid with exceptional promise," Astron Educ Rev, vol. 5, no. 1, pp. 70-88, 2006.

[4] S. R. Hall, I. Waitz, D. R. Brodeur, D. H. Soderholm, and R. Nasr, "Adoption of active learning in a lecture-based engineering class," presented at the 32nd ASEE/IEEE Frontiers in Education Conference, Boston, MA. November 6-9, 2002.

[5] L. J. Robertson, "Twelve tips for using a computerised interactive audience response system," Medical Teacher, vol. 22, pp. 237-239, 2000.

[6] C. Fies and J. Marshall, "Classroom response systems: A review of the literature," Journal of Science Education and Technology, vol. 15, no. 1, pp. 101-109, 2006.

[7] J. E. Caldwell, "Clickers in the large classroom: Current research and best-practice tips," Life Sciences Education, vol. 6, no. 1, pp. 9-20, 2007.

[8] V. Simpson, and M. Oliver, "Electronic voting systems for lectures then and now: A comparison of research and practice," Australasian Journal of Educational Technology, vol. 23, no. 2, pp. 187-208, 2007.

[9] R. W. Preszler, A. Dawe, C. B. Shuster, and M. Shuster, "Assessment of the effects of student response systems on student learning and attitudes over a broad range of biology courses," CBE-Life Sciences Education, vol. 6, no. 1, pp. 29-41, 2007.

[10] D. Brown and M. Warschauer, "From the university to the elementary classroom: Students' experiences in learning to integrate technology in instruction," Journal of Technology and Teacher Education, vol. 14, no. 3, pp. 599-621, 2006.

[11] M. Hammond, E. Fragkouli, I. Suandi, S. Crosson, J. Ingram, P. Johnston-Wilder, S. Johnston-Wilder, Y. Kingston, M. Pope, and D. Wray, "What happens as student teachers who made very good use of ICT during pre-service training enter their first year of teaching?" Teacher Development, vol. 13, no. 2, pp. 93-106, 2009.

[12] F. Paraskeva, H. Bouta, and A. Papagianna, "Individual characteristics and computer self-efficacy in secondary education teachers to integrate technology in educational practice," Computers \& Education, vol. 50, no. 3, pp. 1084-1091, 2008.

[13] Y. Goktas, S. Yildirim, and Z. Yildirim, "Main barriers and possible enablers of ICT integration into preservice teacher education programs," Educational Technology \& Society, vol. 12, no. 1, pp. 193-204, 2009.

[14] P.-S. Hsu and P. Sharma, "A systemic plan of technology integration," Educational Technology \& Society, vol. 9, no. 4, pp. 173-184, 2006.

[15] P. Mishra, M. J. Koehler, and K. Kereluik, "The song remains the same: Looking back to the future of educational technology," Techtrends, vol. 53 , no. 5, pp. 48-53, 2009.

[16] C. P. Lim, C. S. Chai, and D. Churchill, Leading ICT in Education Practices: A Capacity Building Toolkit for Teacher Education Institutions in the Asia-Pacific, Singapore: Microsoft, 2010.

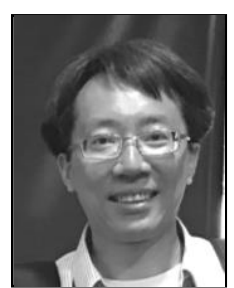

Fu-Hsing Tsai received the MS and $\mathrm{PhD}$ degrees in technology education from the Department of Industrial Technology Education, National Taiwan Normal University, Taiwan. He is currently an associate professor in the Teacher Education Center at National Chiayi University, Taiwan. His research interests include digital game-based learning and e-learning in science and technology education. 